\title{
Screening for Chlamydia trachomatis infection among infertile women in Saudi Arabia
}

This article was published in the following Dove Press journal:

International Journal of Women's Health

5 June 2013

Number of times this article has been viewed

\section{Remah M Kamel \\ Department of Obstetrics and Gynecology, Faculty of Medicine, University of Jazan, Saudi Arabia}

Correspondence: Remah M Kamel

4 Tyndall's Park Road,

Clifton, Bristol, BS8 IPG,

United Kingdom

Tel +44778973 8750

Fax +96673220058

Email rkamel@jazanu.edu.sa
Background: Chlamydia trachomatis infection is a worldwide-distributed sexually transmitted infection that may lead to infertility.

Objectives: This study aims to report the prevalence of Chlamydia trachomatis infection among infertile women in Saudi Arabia.

Patients and methods: A community-based study carried out at the obstetrics and gynecology clinic at Jazan General Hospital, Saudi Arabia. The study group included 640 Saudi infertile women who were aged between 18 and 40 years and who attended the gynecology clinic for infertility examination throughout 1 year of study (from July 1, 2011 to June 30, 2012). The randomized control group included 100 Saudi fertile women who attended the obstetrics clinic for routine antenatal care. All recruited women were screened for chlamydia infection by enzyme-linked immunosorbent assay (ELISA) for detection of serum-specific antibodies and then retested by the McCoy cell culture technique.

Results: The prevalence of Chlamydia trachomatis infection among infertile women was high, at $15.0 \%$. The rate of chlamydia infection detected by ELISA was $9.84 \%$, and it was $12.03 \%$ by the culture method $(P=0.2443)$.

Conclusion: The high prevalence of Chlamydia trachomatis infection among Saudi infertile women demands a national screening program for early detection among infertile couples. ELISA is available as a simple screening test alternative to the culture method.

Keywords: Chlamydia trachomatis, ELISA, McCoy cell culture, infertility, sexually transmitted infection

\section{Introduction}

Chlamydia trachomatis (serotypes $\mathrm{D}-\mathrm{K}$ ) are obligatory intracellular gram-negative bacteria that primarily infect the female cervix, urethra, and fallopian tubes. The majority of infection is asymptomatic and goes undetected, with an increased risk of pelvic inflammatory disease, and is the leading cause of ectopic pregnancy, tubal factor infertility, ${ }^{1-3}$ and chronic pelvic pains.

In Saudi Arabia, the incidence of sexually transmitted infections is low compared with that in developed countries. Gonococcal and nongonococcal urethritis and genital warts have been reported frequently among Saudis, whereas AIDS, syphilis, and genital herpes are frequently reported among non-Saudis. ${ }^{4}$

For diagnosis of chlamydia infection, cell culture of urogenital specimens has been considered the ideal method, although few laboratories could offer this, due to its cost and lack of experience in the cell culture technique. Accurate results depend on the proper sample taking, carrying, storage, and interpretation. Although culture is $100 \%$ 
specific for chlamydia (no false positives), there is a growing observation that culture is not $100 \%$ sensitive. The combination of $100 \%$ specificity and the ability to detect viable organisms makes culture the standard for legal applications such as for sexual assault.

With the availability of more rapid assays during the 1980s, many laboratories started to use enzyme-linked immunosorbent assay (ELISA) due to its lesser demands on cost, skills, and time required for obtaining the results. However, these tests were less sensitive, as detection of antibodies in a single serum sample has frequently been found in the absence of active infection. ${ }^{5}$ Despite the difficulty of differentiating between previous and current infections, the presence of chlamydia-specific antibody (immunoglobulin [Ig]A) is significantly associated with upper genital tract infection, particularly when the antibody titre is high. ${ }^{6,7}$ As sensitivity of the ELISA test is low, this can assist but cannot replace direct antigen detection or isolation of the organism by the culture technique. ${ }^{8}$

Another widely used rapid simple test is enzyme immunoassay. It does not require any sophisticated equipment and it takes only 30 minutes to be completed. It is significantly less sensitive and specific than the laboratorybased tests. Reported sensitivities of rapid tests relative to the culture range from $52 \%$ to $85 \%$ for endocervical swabs, and their specificities are over 95\%.$^{9-11}$ However, rapid tests are not recommended to be used in a low-prevalence population or for asymptomatic women, due to the potential for false positives. Their results should always be confirmed by a laboratory test.

More recent and very sensitive nucleic acid amplification techniques (NAATs), such as polymerase chain reaction and ligase chain reaction, have been used for detection of chlamydia genetic material DNA in cervical and urethral samples. ${ }^{12}$

A further development is nucleic acid hybridization (DNAProbe) tests, which also detect chlamydia genetic material DNA. These tests are very accurate but are not as sensitive as the NAATs. Other diagnostic tests include transcriptionmediated amplification, which amplifies the ribosomal-RNA; strand displacement amplification; and direct fluorescent antibody tests. Papanicolaou smear is not an option for chlamydia screening, as it has poor sensitivity and poor specificity.

Sweden is known to have the best chlamydia screening program in the world. ${ }^{13}$ In the USA, the Centers for Disease Control and Prevention have supported a screening program since 1988. ${ }^{14}$ The phased implementation of a national chlamydia screening program in the UK offers screening for all sexually active women, using NAATs. ${ }^{15}$
Several studies have reported a decline in chlamydia prevalence after early screening and proper treatment. ${ }^{16-18}$ The best evidence to date about the effectiveness of screening for chlamydia infection in preventing pelvic inflammatory disease is a randomized controlled trial conducted in Seattle, USA. ${ }^{19}$ Two Swedish studies have supported its findings. ${ }^{20,21}$ Selective screening is more cost-effective than universal screening, although the latter may be indicated when prevalence of infection is high. ${ }^{22,23}$

The present study aimed to screen Saudi infertile sexually active women in Jazan City, in the southwest region of Saudi Arabia, for possible Chlamydia trachomatis infection.

\section{Patients and methods}

The study was conducted in Jazan General Hospital with the aid of laboratory facilities at the University of Jazan. The study covered a period of 1 year (from July 1, 2011 to June 30, 2012).

The study group included all Saudi married women of primary and secondary infertility, aged between 18 and 40 years, who attended the outpatient gynecology clinic at Jazan General Hospital for infertility examination during the period of study and agreed to participate (signed informed consent). The randomized control group included 100 Saudi married pregnant women who attended the outpatient obstetrics clinic for routine antenatal care during the period of study and agreed to participate (signed informed consent). Randomization was done using the Random Allocation Software ${ }^{\circledR}$ (developed by Saghaei M, MD, Department of Anesthesia, Isfahan University of Medical Sciences, Iran) (Version 1.0, released on May 2004). Structured meetings were conducted with all recruited women, where they received an information sheet about the study and signed an informed consent.

Relevant medical records were reviewed for any possible present and past medical or surgical diseases. For a precise detection of chlamydia infection, two methods have been used for screening - an indirect method for detection of chlamydiaspecific IgG and IgA antibodies in the sera (ELISA), and a direct method for detection of chlamydia organism (McCoy [Medac Gesellschaft für klinische Spezialpräparate mbH, Wedel, Germany] cell culture). All participants' data and screening results were managed confidentially.

About $5 \mathrm{~mL}$ of venous blood was drawn from each participant for measurement of serum chlamydia $\mathrm{IgG}$ and IgA antibodies using a peptide-based enzyme-linked immunosorbent assay (IgG-pELISA Cat No 497/TMB, and IgApELISA Cat No 498/TMB Medac ${ }^{\circledR}$, Wedel, Germany).

Each serum sample had a numerical code so that the clinical condition of the tested woman was unknown to the 
laboratory technician. All kits used in this study were of the same batch. Each kit contained 96 wells, and all tests were performed before their printed expiry dates. The manufacturer's instructions for test procedure were followed when performing the assays. The kits, microplates, controls, buffers, diluent, conjugate, 3,3',5,5'-tetramethylbenzidine substrate, and stop solution were stored at $4{ }^{\circ} \mathrm{C}$ and allowed to stand for 1 hour at room temperature before use. Results were interpreted according to the manufacturer's instructions, issuing a negative, equivocal, or positive result.

The intensity of the color is proportional to the concentration (titer) of the specific antibody in the sample. Cut-off values were calculated according to the manufacturer's instructions. Samples with optical density values located within the gray zone were retested again after 2 weeks in order to determine a titre change. Results remaining in the gray zone were considered negative.

The staff nurse of the outpatient clinic and two general practitioners were taught how to collect endocervical and urethral specimens. We used a cyto-brush (which collects more columnar cells than cotton-tipped swabs). The brush was inserted into the cervical os beyond the squamocolumnar junction 1-2 cm deep, rotated, and removed without touching the vaginal mucosa. The urethral swab was inserted $1 \mathrm{~cm}$ into the urethra, rotated once prior to removal, and placed in a separate tube of 2-sucrose-phosphate culture-transport medium. The examined women were instructed not to urinate within the previous hour (as urination washes out the infected columnar cells).

All collected samples were transported on wet ice to the laboratory of the university within 12 hours of collection. Strict adherence to the standard techniques of collecting specimens has biased the findings toward screening outcomes. As Chlamydia trachomatis is an obligatory intracellular pathogen, a specimen that lacks endocervical cells is discarded, as it will greatly increase the probability of a false negative result.

Specimens were inoculated into coverslip cultures of McCoy cells treated with cycloheximide. The inoculums were centrifuged for 1 hour. We used one-dram shell vials (more sensitive than multiwells). Inoculated cultures were incubated at $37^{\circ} \mathrm{C}$ for 3 days, washed, fixed in methanol, stained with Giemsa, (Medac Gesellschaft für klinische Spezialpräparate $\mathrm{mbH}$, Wedel, Germany) and screened by dark-ground microscopy for possible intracytoplasmic inclusion bodies. Universal precautions were followed when handling such risky specimens, and all our laboratory workers were vaccinated against the hepatitis B virus earlier.

After the screening reports were collected, all participants were informed about their test results and the implications were discussed with the staff nurse. Any woman with a positive result was referred to the clinic for treatment with a notification letter for her husband to be tested and treated.

The collected clinical and laboratory data were stored on Microsoft ${ }^{\circledR}$ Excel spreadsheets for Windows and then analyzed by suitable statistical methods using the StatsDirect ${ }^{\circledR}$ Statistical Software (Version 2.7.9, released on July 9, 2012, StatsDirect Ltd, Cheshire, UK). The data were double-checked carefully during the process of collection, transcription, and computer inputting. No missing data were encountered. For testing significance, $t$-test and Yates-corrected $\chi^{2}$ test with Fisher exact at a confidence interval (CI) of $95 \%$ and a significance level of $5 \%$ were used. A finding was considered of statistical significance if $P$-value $<0.05$.

\section{Results}

The rate of Chlamydia trachomatis infection among Saudi infertile women was higher than its rate among the Saudi fertile women (Table 1 and Figure 1).

The mean age of Saudi infertile women enrolled in this study as the study group was $26.4 \pm 4.8$ years. Women aged less than 25 years (276 women) had an infection rate of $7.81 \%$, whereas those aged between 25 and 40 years (364 women) had an infection rate of $7.19 \%$ (Figure 2). This was not of statistical significance (CI 0.97-2.42, odds ratio [OR] $1.53, P$-value $=0.0581$ ).

Most of the Saudi infertile women had primary infertility (425 women) with an infection rate of $11.72 \%$, whereas 215 women had secondary infertility with an infection rate of $3.28 \%$ (Table 2 and Figure 3 ).

The mean infertility duration for the study group was $3.28 \pm 1.73$ years. Cases with infertility duration less than

Table I Prevalence of Chlamydia trachomatis infection among Saudi women (cases versus controls)

\begin{tabular}{|c|c|c|c|c|c|c|}
\hline \multirow{2}{*}{$\begin{array}{l}\text { Screening } \\
\text { results }\end{array}$} & \multirow{2}{*}{$\begin{array}{l}\text { Cases (infertile women) } \\
n=640\end{array}$} & \multirow{2}{*}{$\begin{array}{l}\text { Controls (fertile women) } \\
n=100\end{array}$} & \multicolumn{2}{|c|}{ Fisher exact $95 \% \mathrm{Cl}$} & \multirow[t]{2}{*}{$P$-value } & \multirow[t]{2}{*}{ OR } \\
\hline & & & Lower & Upper & & \\
\hline Infected & $96(15.0 \%)$ & $4(4.0 \%)$ & I.54 & 16.21 & 0.0015 & 4.24 \\
\hline Not infected & $544(85.0 \%)$ & $96(96.0 \%)$ & & & & \\
\hline
\end{tabular}

Abbreviations: $\mathrm{Cl}$, confidence interval; $\mathrm{n}$, number of women; $\mathrm{OR}$, odds ratio; $P$, significance level. 


\section{Prevalence of chlamydia trachomatis infection among Saudi women \\ (cases versus controls)}

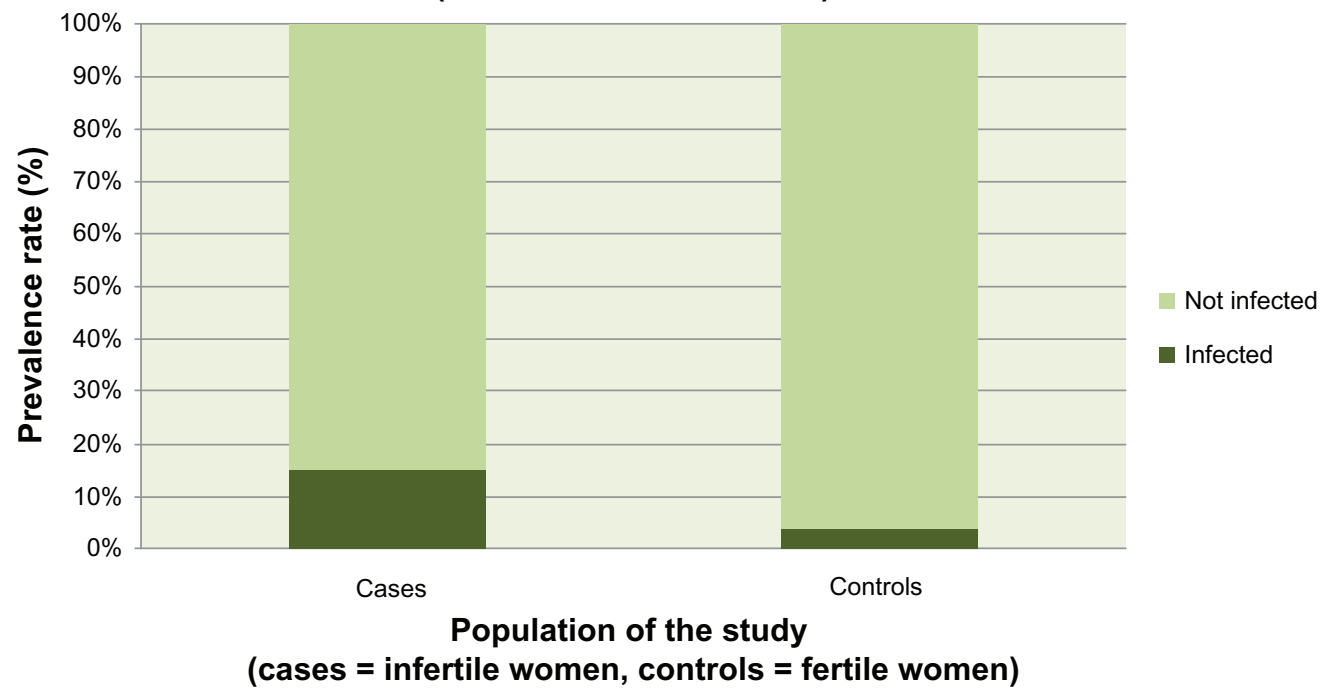

Figure I Prevalence of Chlamydia trachomatis infection among Saudi women (cases versus controls).

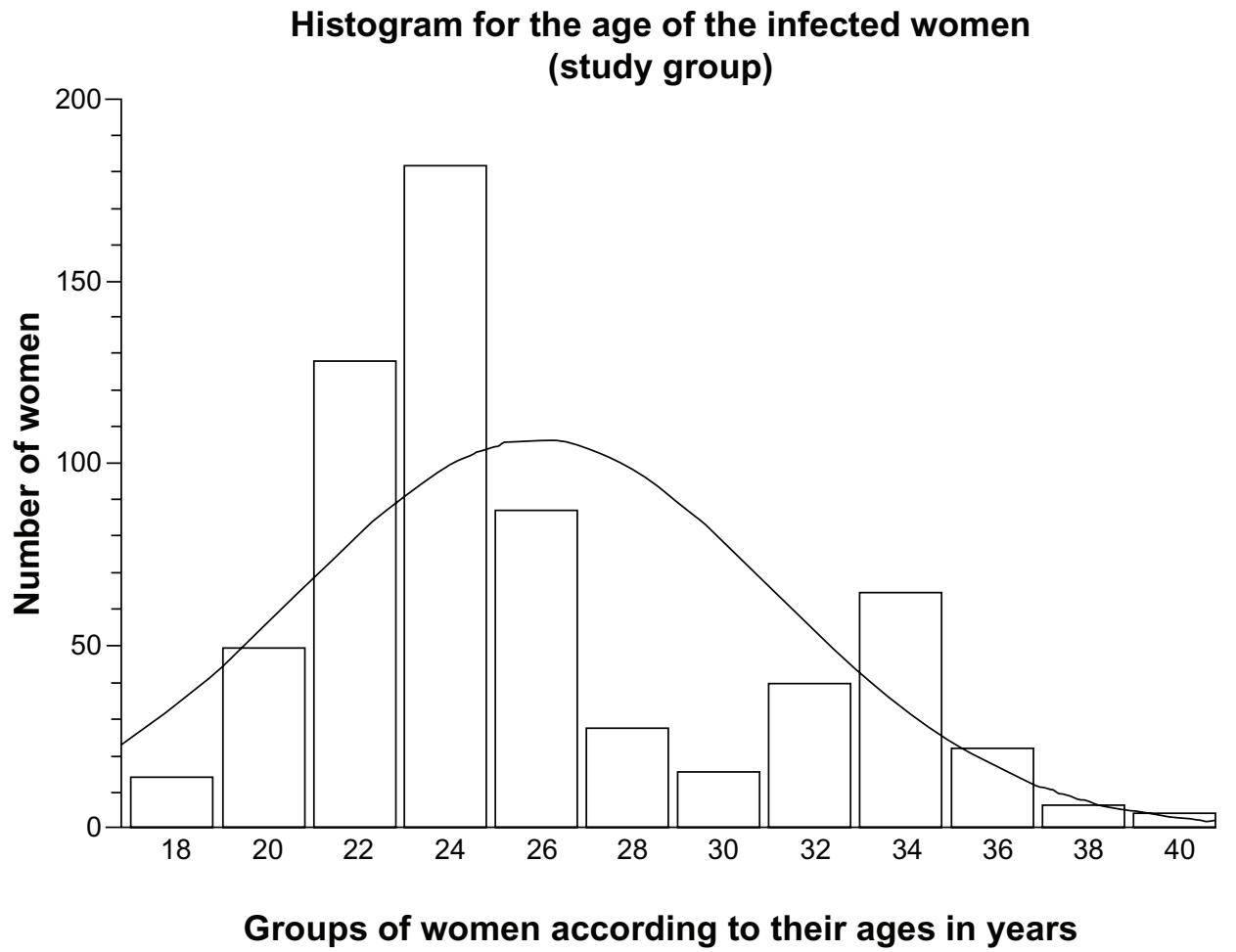

Figure 2 Histogram with distribution curve according to the age of infected Saudi infertile women (positively skewed to the right: ie, more cases at a young age).

Table 2 Prevalence of Chlamydia trachomatis infection among Saudi infertile women (primary versus secondary infertility)

\begin{tabular}{|c|c|c|c|c|c|c|}
\hline \multirow[t]{3}{*}{ Screening results } & \multicolumn{2}{|c|}{ Infertile cases (study group) } & \multicolumn{2}{|c|}{ Fisher exact $95 \% \mathrm{Cl}$} & \multirow[t]{3}{*}{$P$-value } & \multirow[t]{3}{*}{ OR } \\
\hline & Primary & Secondary & Lower & Upper & & \\
\hline & $n=425$ & $n=215$ & & & & \\
\hline Infected & 75 (II.72\%) & $21(3.28 \%)$ & 1.16 & 3.49 & 0.0096 & 1.98 \\
\hline Not infected & $350(54.69 \%)$ & 194 (30.3I\%) & & & & \\
\hline
\end{tabular}

Abbreviations: $\mathrm{Cl}$, confidence interval; $\mathrm{n}$, number of women; $\mathrm{OR}$, odds ratio; $P$, significance level. 


\section{Chlamydia infection among infertile Saudi women (primary versus secondary)}

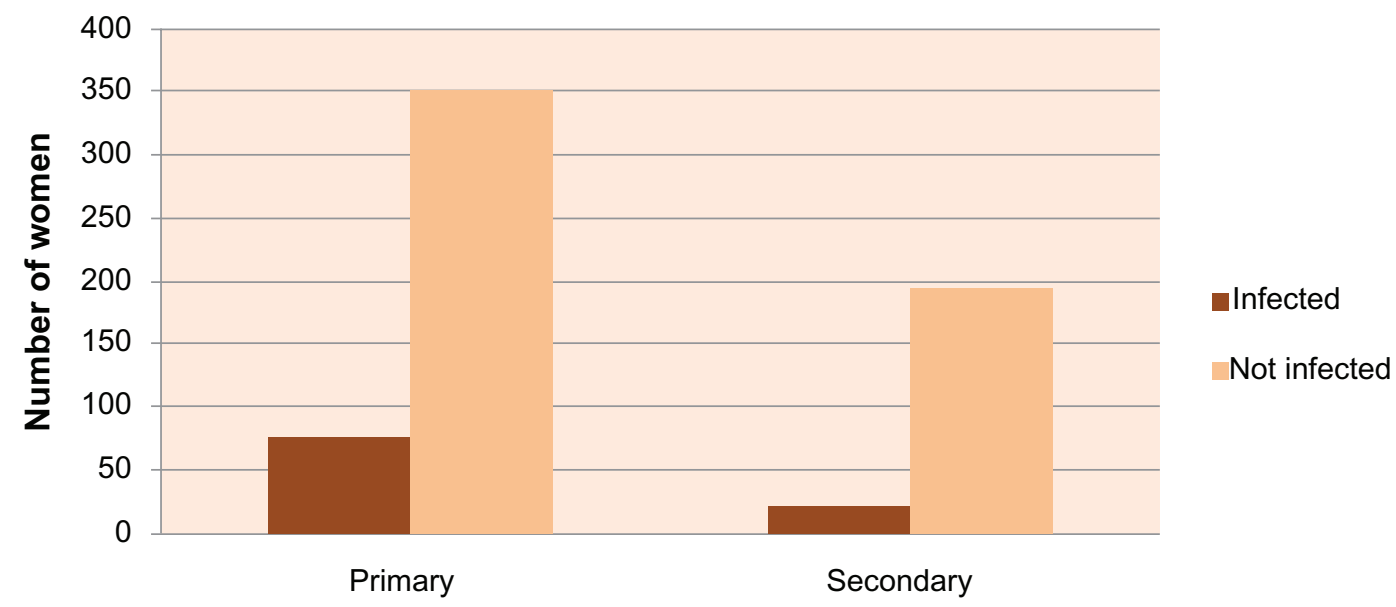

Infertile Saudi women (study group)

Figure 3 Chlamydia trachomatis infection among Saudi infertile women (primary versus secondary).

5 years were 498 women with an infection rate of $12.5 \%$, whereas those with infertility duration longer than 5 years were 142 women with an infection rate of $2.5 \%$. This finding was not of statistical significance $(\mathrm{CI} 0.84-2.86, \mathrm{OR}=1.51$, $P$-value $=0.1832$ )

Among Saudi infertile women, a past history of sexually transmitted infection was mentioned by 165 women (25.78\%), whereas 70 women (10.94\%) reported a previous pelvic surgery. A history of a new husband in the preceding year was mentioned by 47 women $(7.34 \%)$, whereas
23 women (3.59\%) reported a past use of an intrauterine contraceptive cupper-T device.

Most women of the study group were asymptomatic (475 women) with an infection rate of $11.72 \%$, whereas 165 women were symptomatic with an infection rate of $3.28 \%$ (Figure 4 ). This finding was not of statistical significance $(\mathrm{CI} 0.75-2.28, \mathrm{OR}=1.29, P$-value $=0.3777)$.

Inquiry revealed a complaint of painful micturition in 115 women (17.97\%), vaginal discharges in 98 women $(15.31 \%)$, pelvic pains in 96 women $(15.0 \%)$, irregular uterine

\section{Chlamydia infection among women of the study group (symptomatic versus asymptomatic)}

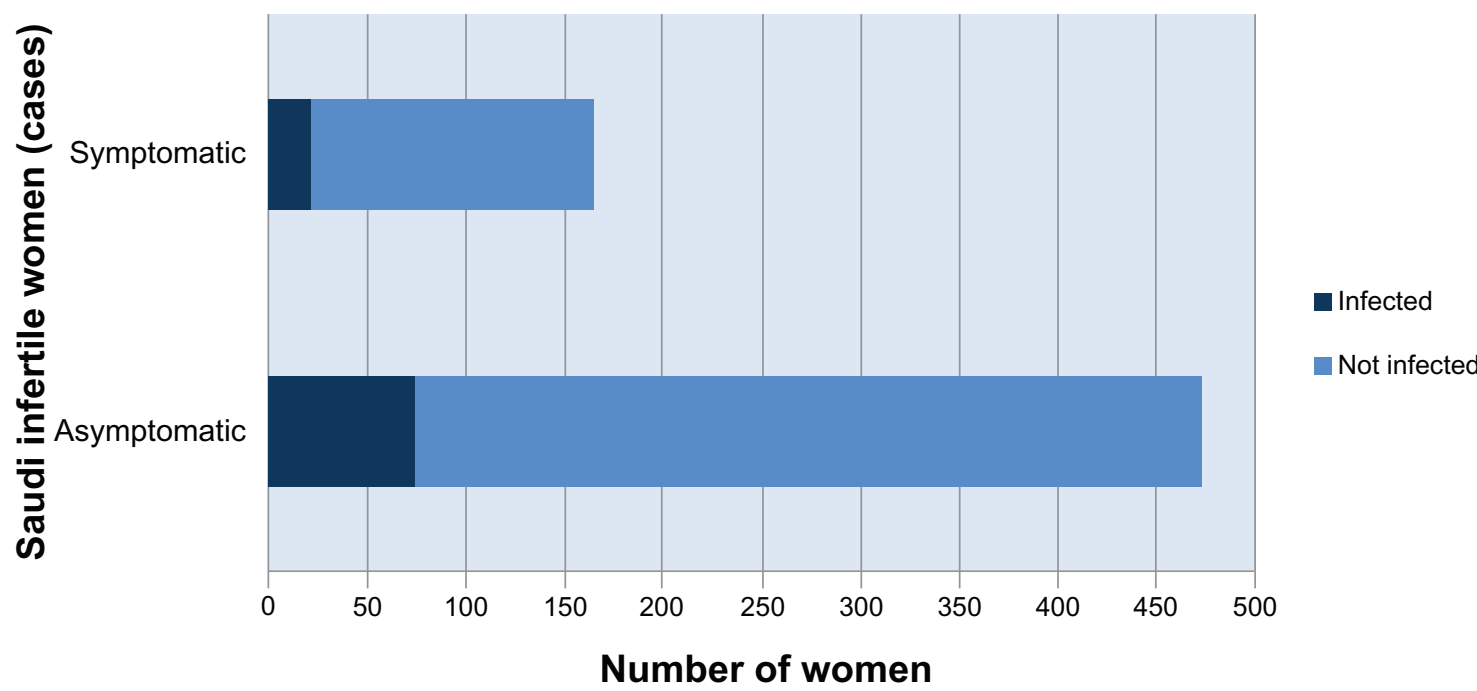

Figure 4 Chlamydia trachomatis infection among Saudi infertile women (symptomatic versus asymptomatic). 
bleeding in 47 women (7.34\%), postcoital bleeding in 27 women $(4.22 \%)$, and urethral discharge in three women $(0.47 \%)$. On pelvic examination the signs were muco-purulent cervicitis in 224 women $(35.0 \%)$, cervical friability in 132 women (20.63\%), and hypertrophic cervix in 56 women (8.75\%).

The rate of detection of Chlamydia trachomatis infection among infertile women using the ELISA test was 9.84\%, whereas it was $12.03 \%$ using the culture technique (Tables 3 and 4, Figure 5). This finding was not of statistical significance (CI 0.55-1.15, OR $=0.798, P$-value $=0.2443$ ). Lastly, a predictive analysis for the screening tests used in this study was done using the StatsDirect ${ }^{\circledR}$ Statistical Software (Table 5).

\section{Discussion}

Chlamydia trachomatis infection is a worldwide-distributed sexually transmitted infection. Prevalence of infection is difficult to estimate without screening, as most of the cases are asymptomatic. Although 929,462 cases of chlamydia infection were reported in the USA, according to the Centers for Disease Control and Prevention, in 2004, ${ }^{14}$ the actual number of cases is thought to be more than 2.8 million per year. ${ }^{24}$ According to the World Health Organization, new cases of chlamydia infection have been estimated globally to be 92 million. ${ }^{25}$ Both health and economic consequences of infection are serious; thus, prevention and early detection are essential.

The findings of this study highlight the need for chlamydia screening programs, as the prevalence of infection among Saudi infertile women in Jazan City, Saudi Arabia, is high (15.0\%).

Sociodemographic risk factors for infection include young age, ${ }^{26,27}$ an urban setting and low income, ${ }^{28}$ having multiple sexual partners ${ }^{29}$ or an infected partner, ${ }^{30}$ nulliparity, ${ }^{31}$ and irregular use of barrier contraceptives or using oral contraceptive pills. ${ }^{32}$

Due to local cultural and social constraints, our study excluded Saudi women aged less than 18 years. Consequently,

Table 3 Interpretation of enzyme-linked immunosorbent assay test results

\begin{tabular}{llll}
\hline IgG & IgA & Test interpretation & $\begin{array}{l}\text { No of } \\
\text { cases }\end{array}$ \\
\hline+ & + & Positive Chlamydia trachomatis infection & 27 \\
+ & - & Past Chlamydia trachomatis infection & 19 \\
- & + & Early Chlamydia trachomatis infection & 3 \\
- & $?$ & Possible early Chlamydia trachomatis infection & 0 \\
$?$ & - & Possible past Chlamydia trachomatis infection & 7 \\
+ & $?$ & Past with possible early Chlamydia trachomatis & 5 \\
& & infection & \\
& + & Early with possible past Chlamydia trachomatis & 2 \\
& & infection & 577 \\
\hline & - & Negative Chlamydia trachomatis infection & 5 \\
\hline
\end{tabular}

Abbreviations: Ig, immunoglobulin; +, positive; -, negative; ?, equivocal.
Table 4 Comparing results of screening tests (Cat.No. 497/TMB and Cat.No. 498/TMB, Medac Gesellschaft für klinische Spezialpräparate mbH Geschäftseinheit Diagnostik, Wedel, Germany) (ELISA versus culture)

\begin{tabular}{llll}
\hline Screening test & Positive & Equivocal & Negative \\
\hline IgG p-ELISA & 51 & 9 & 580 \\
IgA p-ELISA & 32 & 5 & 603 \\
McCoy cell culture & 77 & 0 & 563 \\
\hline
\end{tabular}

Abbreviations: ELISA, enzyme-linked immunosorbent assay; Ig, immunoglobulin.

direct comparison on chlamydia prevalence cannot be made precisely with western studies that include younger women (aged 15-19 years). ${ }^{14}$ Moreover, unmarried Saudi women were excluded from the present study, as the management of any positive cases would create both legal and social problems. Furthermore, routine inquiries about number of sexual partners is not realistic in an Islamic community.

In our study, the rate of infection was $7.81 \%$ for Saudi infertile women aged 18 to less than 25 years. This rate-age association is largely relating to the higher level of sexual activity among young women, whose squamocolumnar junction of the cervix still presents on ectocervix (cervical ectopy), which provides a large target area for infection. ${ }^{33}$ That is why age is used in many countries as a primary determinant for selective chlamydia screening programs. ${ }^{34}$

The prevalence of chlamydia infection among asymptomatic healthy-looking Saudi women is $8.5 \%$ in Riyadh City, ${ }^{35}$ whereas it is $4.0 \%$ in our study in Jazan City, Saudi Arabia.

In this study, positive chlamydia was seen in 75 women out of $425(17.65 \%)$ with primary infertility, and in 21 women out of 215 (9.77\%) with secondary infertility. In an Indian study, positive chlamydia was seen in 20 women out of the $74(27.03 \%)$ with primary infertility, and in eleven women out of the $36(30.56 \%)$ with secondary infertility. ${ }^{36}$

Although chlamydia infection is not yet a fully reportable infectious disease in Saudi Arabia, sera from patients who attended our clinic in Jazan was $9.06 \%$ positive for IgG antibodies and $5.0 \%$ positive for IgA antibodies. In Makkah City, chlamydia IgG antibodies were detected in $8.7 \%$ of pregnant Saudi women, ${ }^{37}$ whereas in our study, IgG antibodies were detected in only $4.0 \%$.

This study is considered the first to screen Saudi infertile women for Chlamydia trachomatis infection as a possible causative factor for their infertility. Lack of chlamydia screening among Saudi women might result from a lack of awareness of the high rate of infection among young asymptomatic women and its serious late complications.

As there is a high prevalence of chlamydia infection among Saudi infertile women (evident in this study) and a 


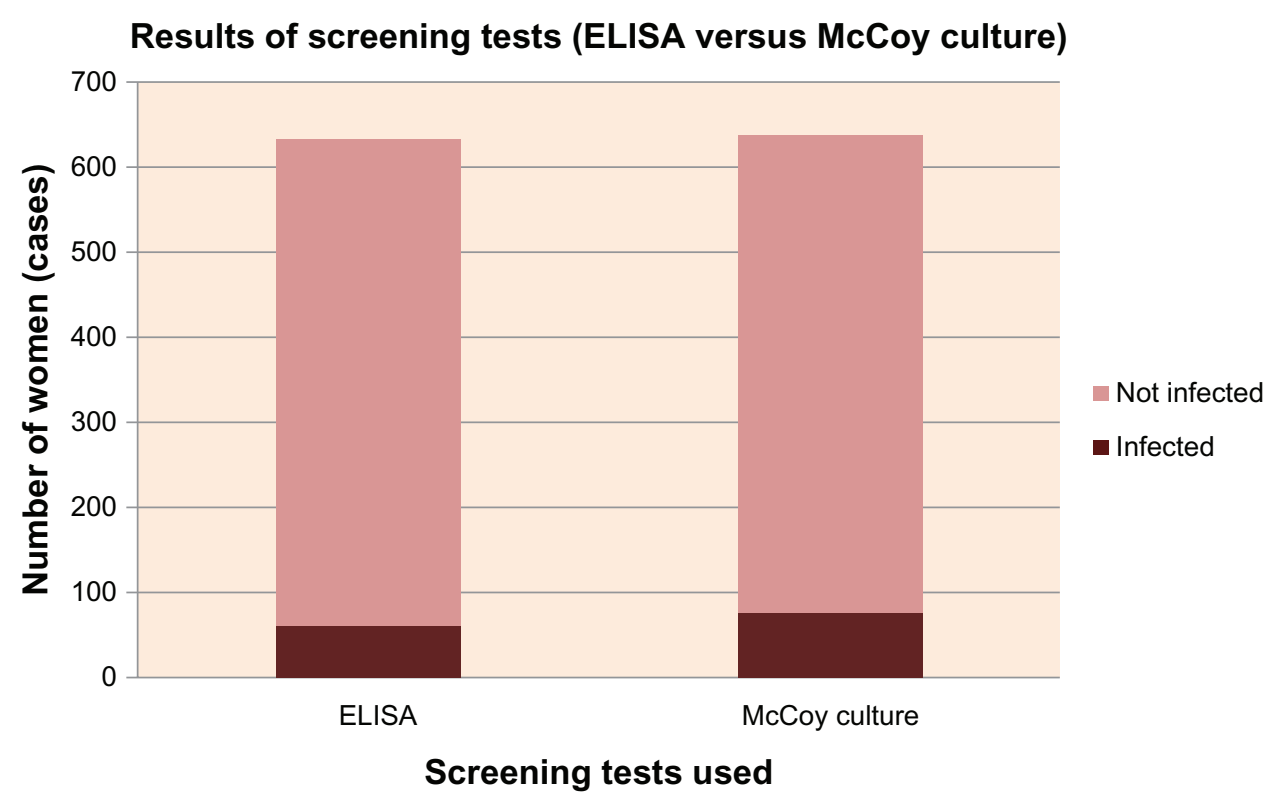

Figure 5 Results of screening tests (Cat.No. 497/TMB and Cat.No. 498/TMB, Medac Gesellschaft für klinische Spezialpräparate mbHGeschäftseinheit Diagnostik, Wedel, Germany) (enzyme-linked immunosorbent assay versus McCoy culture).

high relationship between chlamydia infection and tubal factor infertility (evident in literature), it is mandatory to screen all Saudi infertile women for Chlamydia trachomatis at the start of their infertility examination prior to any invasive procedure.

The limitations of data surveyed in this study include its restriction to the geographic boundaries of Jazan City, to the time frame of 1 year, and to a specific target risk group (Saudi infertile women). There are several questions needed for further research, such as the prevalence of Chlamydia trachomatis infection among the general population in Saudi Arabia, the cost-effectiveness of selective versus universal screening programs, and the effect of a screening program in reducing the rate of infertility.

\section{Conclusion}

The prevalence of Chlamydia trachomatis infection among Saudi infertile women at Jazan City, Saudi Arabia, is high

Table 5 Prediction analysis of screening tests (Cat.No. 497/TMB and Cat.No. 498/TMB, Medac Gesellschaft für klinische Spezialpräparate mbHGeschäftseinheit Diagnostik, Wedel, Germany) (ELISA versus culture)

\begin{tabular}{lll}
\hline Parameter & ELISA & McCoy cell culture \\
\hline Sensitivity & $65.62 \%$ & $80.21 \%$ \\
Specificity & $100.0 \%$ & $100.0 \%$ \\
PPV & $100.0 \%$ & $100.0 \%$ \\
NPV & $94.28 \%$ & $96.63 \%$ \\
\hline
\end{tabular}

Abbreviations: ELISA, enzyme-linked immunosorbent assay; NPV, negative predictive value; PPV, positive predictive value.
(15.0\%). This finding calls for a national screening program for the early detection of Chlamydia trachomatis infection among infertile couples in Saudi Arabia.

The ELISA test seems to be a good alternative to the culture method for screening purposes. It is simple and relatively cheap compared with the McCoy cell culture technique. It has a high specificity $(100 \%)$ and a high negative predictive value $(94.28 \%)$.

\section{Disclosure}

I hereby declare that this work was carried out in accordance with the requirements of the University of Jazan Regulations and Code of Ethics for Research Programs. It was approved by the Research Review Board. Except where indicated by specific reference in the text, this work is my own work. There was no contribution of any other authors. Any views expressed in the study are those of the author. The work was self-funded. In addition, I state that I have no competing interests.

\section{References}

1. Mehanna MT, Rizk MA, Eweiss NY, Ramadan M, Zaki SA, Sadek A, et al. Chlamydial serology among patients with tubal factor infertility and ectopic pregnancy in Alexandria, Egypt. J Sex Transm Dis. 1995;22(5): 317-321.

2. Rajkhowa M, Glass MR, Rutherford AJ, Balen AH, Sharma V, Cuckle HS Trends in the incidence of ectopic pregnancy in England and Wales from 1966 to 1996. BJOG. 2000;107:369-734.

3. Akande VA, Hunt LP, Cahill DJ, Caul EO, Ford WC, Jenkins JM. Tubal damage in infertile women: prediction using chlamydia serology. Hum Reprod. 2003;18(9):1841-1847.

4. Madani TA. Sexually-transmitted infections in Saudi Arabia. J Infectious Dis. 2006;10;6:3. 
5. Watson MA, Templeton A, Russell I, Paavonen J, Mardh P-A, Stary A, et al. The accuracy and efficacy of screening tests for chlamydia trachomatis: a systematic review. J Med Microbiol. 2002;51(11): 1021-1031.

6. Moore DE, Spadoni LR, Foy HM, Wang SP, Daling JR, Kuo CC, et al. Increased frequency of serum antibodies to chlamydia trachomatis in infertility due to distal tubal disease. Lancet. 1982;11:574-577.

7. Fiddelers AA, Land JA, Voss G, Kessels AG, Severens JL. Costeffectiveness of chlamydia antibody tests in subfertile women. Hum Reprod. 2005;20(2):425-432.

8. Chernesky M, Luinstra K, Sellors J, Schachter J, Moncada J, Caul O, et al. Can serology diagnose upper genital tract chlamydia trachomatis infection? Studies on women with pelvic pain, with or without chlamydial plasmid DNA in endometrial biopsy tissue. Sex Transm Dis. 1998;25:14-19.

9. Grossman JH, Rivlin ME, Morrison JC. Diagnosis of chlamydial infection in pregnant women using the Testpack Chlamydia diagnostic kit. J Obstet Gynecol. 1991;77:801-803.

10. Ferris DG, Martin WH. A comparison of three rapid chlamydial tests in pregnant and non-pregnant women. J Fam Pract. 1992;34:593-597.

11. Blanding J, Hirsch L, Stranton N, Wright T, Aarnaes S, de la Maza L, et al. Comparison of the Clearview Chlamydia, the PACE 2 assay, and culture for detection of chlamydia trachomatis from cervical specimens in a low-prevalence population. J Clin Microbial. 1993;31: 1622-1625.

12. Schachter J, McCormack WM, Chernesky MA, Martin DH, Van Der Pol B, Rice PA, et al. Vaginal swabs are appropriate specimens for diagnosis of genital tract infection with chlamydia trachomatis. J Clin Microbial. 2003;41(8):3784-3789.

13. Garland SM, Gertig DM, McInnes JA. Genital chlamydia trachomatis infection in Australia. Med J Australia. 1993;159:90-96.

14. Centers for Disease Control and Prevention (CDCP). Sexually transmitted disease surveillance 2004 supplement, Chlamydia Prevalence Monitoring Project, 2005. Atlanta, US: Department of Health and Human Services. http://www.cdc.gov/std/chlamydia2004/.

15. La Montagne DS, Fenton KA, Randall S, Anderson S, Carter P; on behalf of the National Chlamydia Screening Steering Group. Establishing the National Chlamydia Screening Programme in England: results from the first full year of screening. J Sex Transm Infect. 2004;80(8):335-341.

16. Addiss DG, Vaughn ML, Ludka D, Pfister J, Davis JP. Decreased prevalence of chlamydia trachomatis infection associated with a selective screening program in family planning clinics in Wisconsin. Sex Transm Dis. 1993;20:28-35.

17. Herrmann B, Egger M. Genital chlamydia trachomatis infections in Uppsala County, Sweden, 1985-1993: declining rates for how-much longer? J Sex Transm Dis. 1995;22:253-260.

18. Katz BP, Blythe MJ, Van der Pol B, Jones RB. Declining prevalence of chlamydial infection among adolescent girls. J Sex Transm Dis. 1996;23:226-229.

19. Scholes D, Stergachis A, Heidrich FE, Andrilla H, Holmes KK, Stamm WE. Prevention of pelvic inflammatory disease by screening for cervical chlamydial infection. N Engl J Med. 1996;334:1362-1366.

20. Kamwendo F, Forslin L, Bodin L, Danielsson D. Decreasing incidences of gonorrhea and chlamydia associated acute pelvic inflammatory disease. A 25-year study from an urban area of central Sweden. J Sex Transm Dis. 1996;23:384-391.
21. Egger M, Low N, Smith GD, Lindblom B, Herrmann B. Screening for chlamydial infections and the risk of ectopic pregnancy in a county in Sweden: ecological analysis. BMJ. 1998;316:1776-1780.

22. Sellors JW, Pickard L, Gafni A, Goldsmith CH, Jang D, Mahony JB, et al. Effectiveness and efficiency of selective vs universal screening for chlamydial infection in sexually active young women. Arch Intern Med. 1992;152:1837-1844.

23. Marrazzo JM, Celum CL, Hillis SD, Fine D, DeLisle S, Handsfield HH. Performance and cost-effectiveness of selective screening criteria for chlamydia trachomatis infection in women. Implications for a national chlamydia control strategy. J Sex Transm Dis. 1997;24:131-141.

24. Weinstock H, Berman S, Cates W. Sexually-transmitted diseases among American youth: incidence and prevalence estimates, 2000. Perspect Sex Reprod Health. 2004;36(1):6-10.

25. World Health Organization. Global prevalence and incidence of selected curable sexually transmitted infections: overviews and estimates, 2001. http://www.who.int/hiv/pub/sti/who_hiv_aids_2001.02.pdf

26. Macmillan S, McKenzie H, FlettG, TempletonA. Which women should be tested for chlamydia trachomatis? BJOG. 2000;107(9):1088-1093.

27. Tobin JM. Chlamydia screening in primary care: is it useful, affordable and universal? J Curr Opin Infect Dis. 2002;15:31-36.

28. Gunn RA, Hillis SD, Shirey P, Waterman SH, Greenspan JR. Chlamydia trachomatis infection among Hispanic women in the California-Mexico border area, 1993: establishing screening criteria in a primary care setting. J Sex Transm Dis. 1995;22:329-334.

29. Mosure DJ, Berman S, Kleinbaum D, Halloran ME. Predictors of chlamydia trachomatis infection among female adolescents: a longitudinal analysis. Am J Epidemiol. 1996;144:997-1003.

30. Rietmeijer CA, Van Bemmelen R, Judson FN, Douglas JM Jr. Incidence and repeat infection rates of chlamydia trachomatis among male and female patients in an STD clinic: implications for screening and re-screening. J Sex Transm Dis. 2002;29(2):65-72.

31. Cook RL, St George K, Lassak M, Tran N, Anhalt JP, Rinaldo CR. Screening for chlamydia trachomatis infection in college women with a polymerase chain reaction assay. J Clin Infect Dis. 1999;28:1002-1007.

32. Cottingham J, Hunter D. Chlamydia trachomatis and oral contraceptive use: a quantitative review. J Genito-urinary Med. 1992;68:209-216.

33. Centers for Disease Control and Prevention (CDCP). Sexually transmitted disease surveillance 2003 supplement, Chlamydia Prevalence Monitoring Project, 2004. Atlanta, US: Department of Health and Human Services. http://www.cdc.gov/std/chlamydia2003/chlamydia2003.pdf

34. Miller WC, Hoffman IF, Owen-O'Dowd J, McPherson JT, Privette A, Schmitz JL, et al. Selective screening for chlamydial infection: which criteria to use? Am J Prev Med. 2000;18(2):115-122.

35. Bakir TM, Hossain A, De-Silva S, Siddiqui A, Sengupta BS, El-Sheikh MM, et al. Enzyme immunoassay diagnosis of chlamydia trachomatis infections in diverse patient groups. J Hyg Epidemiol Microbial Immunol. 1989;33(2):189-197.

36. Malik A, Jain S, Hakim S, Shukla I, Rizvi M. 2006. Chlamydia trachomatis infection and female infertility. Indian J Med Res. 2006;123(6):770-775.

37. Ghazi HO, Daghestani MH, Mohamed MF. Seropositivity of chlamydia trachomatis mong Saudi pregnant women in Makkah. J Family and Comm Med. 2006;13(2):61-64.
International Journal of Women's Health

\section{Publish your work in this journal}

The International Journal of Women's Health is an international, peerreviewed open-access journal publishing original research, reports, editorials, reviews and commentaries on all aspects of women's healthcare including gynecology, obstetrics, and breast cancer. The manuscript management system is completely online and includes

\section{Dovepress}

a very quick and fair peer-review system, which is all easy to use. Visit http://www.dovepress.com/testimonials.php to read real quotes from published authors. 